\title{
Perspektif Nilai Budaya dalam Cerpen Banun Karya Damhuri Muhammad
}

\author{
${ }^{1}$ Armet, ${ }^{2}$ Lidya Atsari, ${ }^{3}$ Emil Septia
}

${ }^{1}$ STKIP PGRI Sumatera Barat, Padang, Sumatera Barat

${ }^{2}$ MTsN 4 Tanah Datar, Padangpanjang, Sumatera Barat

${ }^{3}$ STKIP PGRI Sumatera Barat, Padang, Sumatera Barat

${ }^{1}$ armetpgri@gmail.com, ${ }^{2}$ lidya2892@gmail.com, ${ }^{3}$ emil_paradise@yahoo.co.id

Abstract: It is of pivotal importance to maintain cultural values as they are the norms for the behaviors for the majority of society members. This study aimed to determine the cultural value perspectives encorporated in a short story by Banun Damhuri Muhammad. The cultural values themselves are actually the crystallization of the five main issues in human life: (1) the nature of human life, (2) the nature of human creation, (3) the nature of humanity in space and time, (4) the nature of human relations with the natural surroundings, and (5) the nature of human relationships with each others. This research applied a qualitative descriptive analysis method. From the results of the data analysis, three perspectives of cultural values contained in the short story by Banun Damhuri Muhammad were found. They were the essence of life, the human perception of time, and the nature of human relationships with the natural surroundings.

Keywords: culture, perspective, short stories, values, banun, damhuri muhammad

Abstrak: Menjaga nilai budaya adalah hal yang sangat vital karena merupakan norma bagi perilaku sebagian besar anggota masyarakat. Penelitian ini bertujuan untuk mengetahui perspektif nilai budaya yang terdapat dalam cerpen Banun karya Damhuri Muhammad. Nilai-nilai budaya itu sebenarnya merupakan kristalisasi dari lima masalah pokok dalam kehidupan manusia, yakni (1) hakikat dari hidup manusia, (2) hakikat dari karya manusia, (3) hakikat dari kedudukan manusia dalam ruang dan waktu, (4) hakikat dari hubungan manusia dengan alam sekitar, dan (5) hakikat dari hubungan manusia dengan sesamanya. Jenis penelitian ini adalah kualitatif dengan metode analisis deskriptif. Dari hasil analisis data yang diperoleh, terdapat tiga perspektif nilai budaya yang terdapat dalam cerpen Banun karya Damhuri Muhammad, yaitu hakikat hidup, persepsi manusia tentang waktu, dan hakikat dari hubungan manusia dengan alam sekitar.

Kata Kunci: budaya, cerpen, nilai, perspektif, banun, damhuri muhammad

http://ejournal.iainbengkulu.ac.id/index.php/disastra

Copyright ( $) 2021$ Disastra: Jurnal Pendidikan Bahasa dan Sastra Indonesia

All rights reserved 


\section{Pendahuluan}

Sastra adalah hasil jerih payah manusia mediumnya berupa bahasa yang merepresentasikan fenomena sosial, berkenaan dengan pembacanya dan aspekaspek kehidupan manusia yang terekspresi di dalamnya. Sastra merupakan wujud gagasan seseorang melalui pandangan terhadap lingkungan sosial yang beraada di sekelilingnya dengan menggunakan bahasa yang indah. Sastra dikatakan sebagai hasil kreativitas yang penting dan bermanfaat (Armet, 2019). Secara garis besar, manfaat dari karya sastra adalah sebagai hiburan bagi pembaca, dapat mencerminkan kebenaran-kebenaran dalam kehidupan yang nyata, serta menolong pembaca menjadi manusia yang berbudaya.

Sastra adalah ciptaan seseorang dari hasil pikiran dan perasaan yang dia miliki. Karya sastra merupakan hasil imajinasi manusia yang berasal dari kehidupan manusia. Karya sastra tidak muncul dari perbedaan budaya. Ratna (2005:312) memaparkan bahwa hakikat sebuah karya sastra adalah apa yang disebut fiksi atau seringkali fantasi. Imajinasi sastra adalah imajinasi yang didasarkan pada kenyataan. Imajinasi yang dibuat oleh orang lain Pada hakikatnya karya sastra adalah fiksi, tetapi karya sastra dibangun di atas kenyataan.

Selain itu sastra hadir sebagai hasil perenungan pengarang terhadap fenomena yang ada. Sastra sebagai karya fiksi memiliki pemahaman yang lebih mendalam, bukan hanya sebatas cerita khayal atau angan dari pengarang saja, melainkan wujud dari kreativitas pengarang dalam menggali dan mengolah gagasan yang ada dalam pikirannya. Dalam mencapai efektivitas pengungkapan, bahasa sastra disiasati, dimanipulasi, dieksploitasi, dan diberdayakan seoptimal mungkin sehingga tampil dengan bentuk yang plastis, yang berbeda dengan bahasa nonsastra. (Septia et al., 2019).

Karya sastra adalah produk imajinasi, tetapi karya sastra sangat berguna dalam kehidupan. Sebuah karya sastra, bahkan sebuah karya tulis, dapat memberikan kesadaran kepada pembaca akan kebenaran kehidupan. Sebuah karya sastra dapat membawa keceriaan dan kepuasan batin. Karya sastra juga dapat dijadikan sebagai pengalaman kreatif karena siapa saja dapat menuangkan pikiran dan perasaannya ke dalam sebuah karya. Sastra bukan hanya hiburan, tetapi juga keinginan batin untuk dipuaskan. Sastra memungkinkan orang untuk belajar tentang kehidupan.

Salah satu jenis karya sastra prosa adalah cerita pendek. Cerpen merupakan prosa yang pendek dan padat, unsur-unsur cerita semuanya berpusat pada satu peristiwa utama, sehingga jumlah pelaku yang terlibat terbatas dan keseluruhan cerita memberikan kesan private. Peristiwa menjadi lebih banyak dan menggugah seiring dengan berlalunya konteks dan ingatan.

Cerpen (dalam pengertian modern) cenderung lebih padat dan logis dibandingkan novel atau novel sejenis novel. Karena kesederhanaannya, cerita pendek blockbuster lebih luas daripada novel penuh dan didasarkan pada keterampilan sastra seperti karakter, plot, subjek, bahasa, dan ide. Sejarah dapat dibentuk menjadi banyak genre. Selanjutnya menurut Abrams (Nurgiyantoro 2015:5) juga mengatakan 
bahwa sesuai dengan namanya, cerpen secara harfiah berarti "kebaruan kecil" dan harus dipahami sebagai cerpen. Jika Anda membacanya, setting dan kilas baliknya berhubungan dengan sebuah bagian. karakter dalam suatu situasi.

Cerita pendek sebagai salah satu jenis karya sastra ternyata dapat memberikan manfaat kepada pembacanya. Diantaranya, dimungkinkan untuk memberikan pengalaman alternatif, kesenangan, mengembangkan imajinasi, mengembangkan pemahaman tentang perilaku manusia, dan memberikan pengalaman universal. Pengalaman universal ini tentunya erat kaitannya dengan kehidupan dan kehidupan manusia dan kemanusiaan. Bisa masalah pernikahan, cinta, tradisi, agama, persahabatan, masyarakat, politik, pendidikan, dan lain-lain. Orang yang membacanya merasa seolah-olah sedang melihat gambaran miniatur kehidupan manusia dan merasa sangat dekat dengan isu-isu yang terkait dengannya. Akibatnya, pembaca terjebak dalam plot dan masalah. Bahkan, perasaan dan pikirannya sering berubah dalam soal cerita yang dibacanya. Pada titik ini, pembaca akan tertawa, sedih, senang, kecewa, marah, dan mungkin menyukai atau membenci karakter tersebut.

Cerita pendek sering berfokus pada suatu peristiwa dan mencakup periode waktu yang singkat dengan satu plot, jumlah karakter yang terbatas. Dalam bentuk yang lebih panjang dari fiksi, cerita cenderung mengandung beberapa elemen kunci dari struktur dramatis: deskripsi (setting, situasi, pengenalan karakter utama), kompleksitas (konfrontasi dan peristiwa), Narasi memperkenalkan karakter utama). kompleksitas (peristiwa dalam sejarah yang menyebabkan konfrontasi); aksi, krisis (untuk saat-saat menentukan karakter utama dan gerakan mereka); Klimaks (Poin cerita mencakup poin yang paling menarik dan tindakan yang paling penting atau paling penting dalam hal konfrontasi); resolusi (bagian dari cerita dan konflik diselesaikan) dan etika.

Nilai adalah penentu yang mengkomunikasikan ide-ide individu tentang apa yang benar, baik, dan diinginkan. Sutarjo (2013: 56) menyatakan bahwa nilai berasal dari bahasa Latin yaitu value're yang artinya berguna, mampu akan, berdaya, berlaku sehingga nilai diartikan sebagai sesuatu yang dipandang baik, bermanfaat dan paling benar menurut keyakinan seseorang atau sekolompok orang. Nilai adalah kualitas suatu hal yang menjadikan hal itu disukai, diinginkan, dikejar, dihargai, berguna dan dapat membuat orang yang menghayatinya menjadi bermartabat. Sebuah nilai merupakn sebuah konsepsi, eksplisit atau implisit yang menjadi milik khusus seorang atau ciri khusus suatu kesatuan sosial (masyarakat) menyangkut sesuatu yang diingini bersama (karena berharga) yang mempengaruhi pemilihan sebagai cara, alat dan tujuan sebuah tindakan.

Kluckhohn dalam Pelly (1994) mengemukakan bahwa nilai budaya merupakan sebuah konsep ruang lingkup luas yang hidup dalam alam pikiran sebagian besar warga masyarakat, mengenai apa yang berharga dalam hidup. Rangkaian konsep itu satu sama lain saling berkaitan dan merupakan sebuah sistem nilai-nilai budaya.

Budaya adalah cara hidup yang dikembangkan, dibagikan, dan dihidupi 
oleh orang-orang dari kelompok tersebut secara turun-temurun. Budaya terdiri dari banyak elemen kompleks, termasuk sistem agama dan politik, adat istiadat, bahasa, peralatan, pakaian, bangunan, dan karya seni. Bahasa, seperti halnya budaya, merupakan bagian penting dari manusia, sehingga banyak orang cenderung menganggapnya sebagai warisan.

Kebudayaan mengandung pengertian yang lebih luas, termasuk sentimen nasionalis yang kompleks. Kompleksitas perkembangan budaya meliputi pengetahuan, kepercayaan, kesenian, hukum, moral, adat istiadat (adat) dan ciri-ciri lain yang dapat diperoleh sebagai anggota masyarakat. Budaya adalah pengetahuan kolektif yang dimiliki bersama oleh warga suatu masyarakat. Pengetahuan diambil sebagai kebenaran untuk dijadikan pedoman. Semua ini opsional dan digunakan dalam konteks, tergantung pada kebutuhan dan masalah yang dihadapi.

Secara fungsional sistem nilai ini mendorong individu untuk berperilaku seperti apa yang ditentukan. Mereka percaya, bahwa hanya dengan berperilaku seperti itu mereka akan berhasil (Kahl, dalam Pelly:1994). Sistem nilai itu menjadi pedoman yang melekat erat secara emosional pada diri seseorang atau sekumpulan orang, malah merupakan tujuan hidup yang diperjuangkan. Oleh karena itu, merubah sistem nilai manusia tidaklah mudah, dibutuhkan waktu. Sebab, nilai - nilai tersebut merupakan wujud ideal dari lingkungan sosialnya. Dapat pula dikatakan bahwa sistem nilai budaya suatu masyarakat merupakan wujud konsepsional dari kebudayaan mereka, yang seolah olah berada diluar dan di atas para individu
Volume 3, Nomor 2, Juli 2021

ISSN 2655-3031 (P), 2655-7851 (O)

DOI: http://dx.doi.org/10.29300/disastra.v3i2.4497

warga masyarakat itu. Perkembangan suatu kebudayaan tidak terlepas dari usaha-usaha menggali, mewariskan, dan melestarikan serta dapat dilakukan melalui pendidikan baik formal mupun kasual.

Kluckhohn

(dalam

Koentjaraningrat,2009:154) menegaskan bahwa tiap sistem nilai budaya dalam tiap kebudayaan mengandung lima masalah dasar dalam kehidupan manusia. Kelima masalah dasar dalam kehidupan manusia yang menjadi landasan bagi kerangka variasi sistem nilai budaya adalah sebagai berikut. Pertama, hakikat hidup. Kebudayaan yang memandang hidup manusia pada hakikatnya suatu hal yang buruk dan menyedihkan, karena itu harus dihindari. Kebudayaan kebudayaan yang terpengaruh oleh agama Budha misalnya dapat disangka mengonsepsikan hidup itu sebagai suatu hal yang buruk. Pola tindakan manusia akan mementingkan segala usaha untuk menunjuk kearah tujuan untuk dapat memadamkan hidup itu, dan meremehkan segala tingkatan yang hanya mengekalkan rangkaian kelahiran kembali. Kebudayaankebudayaan lain memandang hidup manusia itu pada hakikatnya buruk, tetapi manusia dapat mengusahakan untuk menjadikannya suatu hal yang baik dan menggembirakan.

Kedua, hakikat karya Budaya menganggap bahwa karya manusia pada hakikatnya adalah pencipta kehidupan, dan budaya lain menganggap esensi kerja manusia sebagai tempat terhormat dalam masyarakat. Ketiga, persepsi manusia tentang waktu, budaya dianggap penting dalam kehidupan masyarakat di masa lalu. Dalam budaya yang sama, orang lebih cenderung memandu contoh perilaku dan peristiwa masa lalu. Di sisi lain, ada banyak 
budaya yang memiliki pandangan sempit tentang waktu. Warga dari budaya yang sama tidak kesulitan memikirkan masa lalu dan masa depan. Sementara itu, budaya lain tertarik pada prospek kemungkinan masa depan. Perencanaan untuk hidup sangat penting dalam budaya seperti itu.

Keempat, pandangan manusia terhadap alam. Budaya yang melihat alam sebagai sangat kuat, dan manusia dapat melepaskannya tanpa banyak usaha. Di sisi lain, banyak budaya lain menganggap alam sebagai inisiatif manusia, dan manusia harus terus-menerus berusaha menaklukkan alam. Budaya lain percaya bahwa manusia hanya dapat menemukan harmoni dengan alam. Kelima, hakikat hubungan manusia dengan sesamanya. Budaya yang sangat mementingkan hubungan vertikal antara manusia dengan sesamanya. Dalam tingkah lakunya manusia yang hidup dalam suatu kebudayaan serupa akan berpedoman kepada tokoh-tokoh pemimpin, orangorang senior, atau atasan. Kebudayaan lain lebih mementingkan hubungan even antara manusia dengan sesamanya. Orang dalam suatu kebudayaan serupa akan merasa tergantung kepada sesamanya. Usaha untuk memelihara hubungan baik dengan tetangganya dan sesamanya merupakan suatu hal yang dianggap sangat penting dalam hidupnya.

Cerpen Banun merupakan salah satu cerpen yang ditulis oleh Damhuri Muhammad. Cerpen ini mengisahkan tentang seorang wanita yang kuat dengan keinginan yang kuat hingga ia bisa sukses di kampungnya. Anak-anaknya bisa dikuliahkan sampai ke perguruan tinggi. Banun mengajarkan semua anak untuk tidak membeli semuanya. Dia suka melakukannya sendiri. Tabungan Banun
Volume 3, Nomor 2, Juli 2021

ISSN 2655-3031 (P), 2655-7851 (O)

DOI: http://dx.doi.org/10.29300/disastra.v3i2.4497

bisa membuatnya kaya. Cerpen Banun juga memiliki bahasa yang baku, indah dan mudah dipahami oleh pembaca. Cerpen ini mengandung nilai budaya, berdasarkan hal tersebut cerpen ini layak untuk diteliti.

Berdasarkan uraian di atas, peneliti ingin melakukan penelitian mengenai perspektif nilai budaya yang terdapat dalam cerpen Banun karya Damhuri Muhammad. Tujuan penelitian ini adalah untuk mengetahui nilai budaya apa saja yang terdapat dalam cerpen Banun ini.

\section{Metode Penelitian}

Penelitian ini merupakan penelitian kualitatif. Penelitian kualitatif memberikan perhatian terhadap informasi alamiah, informasi dalam hubunganya dengan konteks keberadaannya (Ratna, 2004: 47). Metode adalah cara yang dipilih oleh peneliti dengan mempertimbangkan bentuk, isi, sebagai subyek penelitian (Endraswara 2003: 8). Metode yang digunakan dalam penelitian ini adalah metode deskriptif, karena peneliti ingin menggambarkan atau mendeskripsikan informasi yang diperoleh. Artinya informasi yang diperoleh dipaparkan menggunakan customized organization individualized structure, ataupun kalimat dan bukan dalam bentuk angka-angka atau hitungan.

Hal tersebut sesuai dengan pendapat Moleong (2012) yang mengatakan bahwa data dikumpulkan adalah berupa kata-kata, gambar dan bukan angka-angka. Data dalam penelitian ini adalah teks cerpen Banun karya Damhuri Muhammad. Untuk mendapatkan data sesuai permasalahan, teknik pengumpulan data yang digunakan adalah teknik studi dokumenter. Teknik dokumenter merupakan cara mengumpulkan data yang dilakukan 
dengan kategorisasi dan klarifikasi bahanbahan tertulis yang berhubungan dengan masalah penelitian, baik dari sumber dokumen maupun buku-buku, koran, majalah dan lain-lain. Pengumpulan data dengan cara: a) cerpen Banun karya Damhuri Muhammad, b) menggarisbawahi data yang berupa nilai-nilai budaya dalam cerpen tersebut, c) mencatat semua data yang sudah digarisbawahi dalam kartu data, dan d) mengkategorikan data yang berupa nilai-nilai budaya yang terdapat dalam cerpen Banun karya Damhuri Muhammad.

\section{Hasil dan Pembahasan}

Tokoh adalah orang yang mengalami peristiwa-peristiwa di dalam cerita yang digambarkan melalui alur. Tokoh juga dapat dibedakan berdasarkan peranannya masing-masing dan penokohannya dapat ditentukan oleh seberapa penting sudut pandangnya dengan latar belakangnya. Adapun tokoh-tokoh dalam cerpen Banun karya Damhuri Muhammad adalah Banun, Rimah, Nami, Palar dan Zubaidah (istri Palar).

Jones (dalam Nurgiyantoro, 1995: 165) menjelaskan penokohan adalah penggambaran yang jelas tentang seseorang yang ditampilkan dalam sebuah cerita. Penokohan ini berkaitan dengan karakter yang diperankan oleh tokoh dalam cerita.

Berikut penokohan dalam cerpen Banun adalah sebagai berikut. Banun, adalah sosok perempuan tua yang tangguh dan pekerja keras. Ia menghidupi keempat orang anaknya dengan bertani. Berkat usaha dan kerja kerasnya itulah ia bisa membesarkan dan menyekolahkan anaknya hingga sarjana. Dalam kehidupan seharihari, Banun mempunya prinsip selagi bisa didapatkan sendiri, kenapa harus membeli.
Volume 3, Nomor 2, Juli 2021

ISSN 2655-3031 (P), 2655-7851 (O)

DOI: http://dx.doi.org/10.29300/disastra.v3i2.4497

Namun karena prinsipnya itu, orang sekelilingnya menganggap Banun kikir. Padahal sebenarnya Banun tidak kikir.

Rimah adalah putri bungsu Banun. Rimah sering tak tahan mendengar omongan yang mengatakan ibunya kikir. Rimah pernah menawarkan membelikan kompor gas untuk ibunya agar ibunya tak disebut kikir. Namun ibunya tetap menolak tawaran Rimah.

Palar adalah lelaki yang telah memberikan Banun julukan kikir. Palar memberikan julukan itu karena ia sakit hati atas penolakan Banun terhadap dirinya. Begitupun ketika pinangannya untuk Rimah, putri bungsu Banun, kembali ditolak oleh Banun.

Nami adalah putri kedua Banun. Sama seperti Rimah, Nami juga tidak tahan mendengar omongan orang yang selalu mengatai ibunya kikir. Ada beberapa nilainilai budaya yang terdapat dapat di dalam cerpen Banun sebagai berikut.

\section{Hakikat Hidup}

Inti dari kehidupan manusia adalah mencoba untuk memenuhi kebutuhan mereka sampai mereka puas sampai batas tertentu. Keterbatasan benda yang digunakan sebagai alat pemuasan dipadu dengan keterbatasan kemampuan orang untuk berbisnis telah mendorong orang untuk bekerja sama dengan orang lain.

Dalam cerpen Banun, hakikat hidup yang digambarkan adalah hidup itu buruk, tetapi manusia wajib berikhtiar supaya hidup itu menjadi baik. Hal ini dapat kita lihat melalui tokoh Banun. Banun yang awalnya hanya seorang petani biasa berhasil memiliki hampir separuh lahan sawah menjadi miliknya. Berkat kerja kerasnya jugalah ia berhasil membesarkan 
dan meyekolahkan keempat anaknya hingga sarjana. Hal itu dapat dilihat pada kutipan berikut ini.

"Lagipula apa yang tak bisa tumbuh di tanah kampung itu akan ditanamnya, agar ia selalu terhindar dari keharusan membeli. Dengan begitu, penghasilan dari panen padi, kelak bakal terkumpul, guna membeli lahan sawah yang lebih luas lagi. Dan, setelah bertahun-tahun menjadi orang tani, tengoklah keluarga Banun kini. Hampir separuh dari lahan sawah yang terbentang di wilayah kampung tempat ia lahir dan dibesarkan, telah jatuh ke tangannya. Orang-orang menyebutnya tuan tanah".

Selanjutnya data yang berkaitan dengan hakikat hidup adalah sebagai berikut.

"Hasil sawah yang tak seberapa itu hendak dibawa mati, Mak?" tanya Rimah suatu ketika. Kuping anak gadis Banun itu panas karena gunjing perihal Banun Kikir tiada kunjung reda. "Mak tak hanya kikir pada orang lain, tapi juga kikir pada perut sendiri," gerutu Nami, anak kedua Banun."Tak usah hiraukan gunjingan orang! Kalau benar apa yang mereka tuduhkan, kalian tak bakal mengenyam bangku sekolah, dan seumur-umur akan jadi orang tani," bentak Banun.

Berdasarkan kutipan tersebut, terlihat tokoh Banun selalu menjadi gunjingan orang yang mengatakan Banun kikir. Anak-anak Banun juga sering mendengar gunjingan orang kampungnya sehingga telinga anak Banun menjadi panas. Tapi Banun menjelaskan kepada anaknya bahwa dengan hasil sawah yang
Volume 3, Nomor 2, Juli 2021

ISSN 2655-3031 (P), 2655-7851 (O)

DOI: http://dx.doi.org/10.29300/disastra.v3i2.4497

sudah ia garap bisa menyekolahkan semua anaknya.

\section{Persepsi Manusia tentang Waktu}

Dalam cerpen Banun ada dua persepsi tentang waktu yang dapat dilihat. Pertama, dari tokoh Banun. Persepsi waktu yang tergambar ialah berorientasi ke masa depan. Semua yang Banun lakukan sematamata agar kehidupan anak-anaknya lebih baik. ketika Banun menolak lamaran putra Palar itu juga agar kehidupan putrinya nanti tidak susah karena ia tahu betul siapa keluarga Palar. Hal itu dapat kita lihat pada kutipan berikut.

"Tapi, bagaimana mungkin Rustam
akan memberi contoh cara bertani
modern, sementara sawahnya sudah
ludes terjual? Kalau memang benar
Palar orang tani yang
sesungguhnya, ia tidak akan
gampang menjual lahan sawah,
meski untuk mencetak Insinyur
Pertanian yang dibanggakannya itu.
Apalah guna Insinyur Pertanian bila
tidak mengamalkan laku orang
tani? Banun menolak pinangan itu
bukan karena Palar sedang terbelit
hutang, tidak pula karena ia sudah
jadi tuan tanah, tapi karena
perangai buruk Palar yang
dianggapnya sebagai penghinaan
pada jalan hidup orang tani”.

Kedua, dari tokoh Palar. Persepsi waktu yang tergambar adalah orientasi ke masa lalu. Ia menjadi pendendam kepada Banun karena sakit hati lamarannya pernah ditolak oleh Banun. Begitupun ketika ia melamar Rimah untuk putranya., lamarannya ditolak kembali oleh Banun. Hal ini dapat kita lihat dari kutipan berikut. 
"Rupanya penolakan Banun telah menyinggung perasaan Palar. Lelaki itu merasa terhina. Mentang-mentang sudah kaya, Banun mentah-mentah menolak pinangannya. Dan, yang lebih menyakitkan, ini bukan penolakan yang pertama. Tiga bulan setelah suami Banun meninggal, Palar menyampaikan niatnya hendak mempersunting janda kembang itu. Tapi, Banun bertekad akan membesarkan anak-anaknya tanpa suami baru. Itu sebabnya Palar menggunakan segala siasat dan muslihat agar Banun termaklumatkan sebagai perempuan paling kikir di kampung itu".

\section{Pandangan Manusia terhadap} Alam

Budaya yang melihat alam sebagai sangat kuat, dan manusia dapat melepaskannya tanpa banyak usaha. Di sisi lain, banyak budaya lain menganggap alam sebagai inisiatif manusia, dan manusia harus terus-menerus berusaha menaklukkan alam. Budaya lain percaya bahwa manusia hanya dapat menemukan harmoni dengan alam.

Dalam cerpen ini dapat kita lihat persepsi tentang alam, bagaimana manusia menjaga keselarasan dengan alam. Dari cerpen ini dapat dilihat bagaimana sosok Banun menjaga keselarasan dengan alam. Hal ini dapat kita lihat pada kutipan berikut.

"Sejak itulah Banun
menyingkapkan rahasia hidupnya
pada anak-anaknya, termasuk pada
Rimah, anak bungsunya itu. Ia
menjelaskan kata "tani" sebagai
penyempitan dari "tahani", yang

Volume 3, Nomor 2, Juli 2021

ISSN 2655-3031 (P), 2655-7851 (O)

DOI: http://dx.doi.org/10.29300/disastra.v3i2.4497

bila diterjemahkan ke dalam bahasa orang kini berarti: "menahan diri." Menahan diri untuk tidak membeli segala sesuatu yang dapat diperoleh dengan cara bercocok tanam. Sebutlah misalnya, sayur-mayur, cabai, bawang, seledri, kunyit, lengkuas, jahe".

"Maka, selepas kesibukannya menanam, menyiangi, dan menuai padi di sawah milik sendiri, dengan segenap tenaga yang tersisa, Banun menghijaukan pekarangan dengan bermacam-ragam sayuran, cabai, seledri, bawang, lengkuas, jahe, kunyit, gardamunggu, jeruk nipis, hingga semua kebutuhannya untuk memasak tersedia hanya beberapa jengkal dari sudut dapurnya”.

Pada permulaan cerpen, kita menilai bahwa Banun merupakan sosok yang sangat kikir. Pengenalan tokoh Banun diawal secara jelas menyebutkan bahwa Banun memiliki sifat yang sangat kikir. Sifat kikirnya itu dikenal oleh seluruh warga kampung. Namun setelah selesai membaca cerpen, semua pandangan di awal itu berubah. Di akhir dapat disimpulkan bahwa Banun ternyata tidak kikir seperti penggambaran awal. 'Kekikiran' Banun ternyata karena ulah Palar yang menaruh dendam kepadanya lantaran lamarannya pernah ditolak oleh Banun. Semua yang dilakukan oleh Banun karena ia hemat. Ia mengingat pesan mendiang suaminya tentang makna tani yang berasal dari tahani. Jadi selama ia bisa menahan segalanya untuk "ditahani" maka ia akan menjadi seorang tani yang sukses. 
Simpulan

Nilai budaya merupakan konsepsikonspei yang hidup dalam dalam alam pikiran sebagian besar masyarakat, mengenai hal-hal yang harus mereka anggap amat bernilai dalam hidup. Karena itu, suatu sistem nilai budaya biasanya berfungsi sebagai pedoman tertinggi bagi kelakuan manusia. Dalam karya sastra, alur cerita tidak akan pernah terlepas dari nilai budaya karena karya sastra itu, misalnya novel atau cerpen tercipta tidak terlepas dari realita kehidupan manusia.

Sistem nilai budaya terkait lima masalah pokok dalam kehidupan manusia. Kelima masalah pokok itu adalah : (1) masalah mengenai hakikat dari hidup manusia, (2) masalah mengenai hakikat dari karya manusia, (3) masalah mengenai hakikat dari kedudukan manusia dalam ruag dan waktu, (4) masalah mengenai hakikat dari hubungan manusia dengan alam sekitarnya, dan (5) masalah mengenai hakikat dari hubungan manusia dengan sesamanya. Hasil analisis data yang diperoleh terdapat tiga orientasi nilai budaya yang terdapat dalam cerpen Banun karya Damhuri Muhammad, yaitu hakikat hidup, persepsi manusia tentang waktu, dan hakikat dari hubungan manusia dengan alam sekitar.

\section{Daftar Pustaka}

Abdurahman. (2011). Nilai-Nilai Budaya dalam Kaba Minangkabau. Padang: UNP Press.

Armet, A. (2019). "Multikonflik dalam Novel Lampuki Karya Arafat Nur". Magistra Andalusia: Jurnal Ilmu Sastra, 1(1).
Volume 3, Nomor 2, Juli 2021

ISSN 2655-3031 (P), 2655-7851 (O)

DOI: http://dx.doi.org/10.29300/disastra.v3i2.4497

https://doi.org/10.25077/majis.1.1.2. 2019

Burhan, N. (2015). Teori Pengkajian Fiksi. Yogyakarta: Gajah Mada University Press.

Endraswara, S. (2003). Metodologi Penelitian Sastra: Epistemologi, Model, Teori, dan Aplikasi (Edisi Revisi). Yogyakarta: FBS Universitas Negeri Yogyakarta.

Koentjaraningrat, (2009). Pengantar Ilmu Antropologi. Jakarta: Rineka Cipta.

Moleong, L. (2012). Metodologi Penelitian Kualitatif. Bandung: PT Remaja Rosdakarya.

Muhammad,D.(2010).http://damhurimuha mmad.blogspot.co.id/2010/10/banu n.html

Mulyana, R. (2004). Mengartikulasikan Pendidikan Nilai. Bandung: Alfabeta.

Nurgiyantoro, B. (2015). Teori pengkajian fiksi. Yogyakarta: Gajah Mada Press.

Pelly, U. (1994). Teori-Teori Ilmu Sosial Budaya. Departemen Pendidikan dan Kebudayaan, Jakarta. Penyusun, Tim. 2008. Kamus Besar Bahasa Indonesia. Pusat Bahasa, Jakarta.

Ratna, K.N. (2010). Teori, Metode, dan, Teknik Penelitian Sastra: Dari Strukturalisme hingga Postrukturalisme Perspektif 
LDJDISASTRRA

Wacana Naratif. Yogyakarta:

Pustaka Pelajar.

Ratna, K.N. (2005). Sastra dan Cultural Studies: Representasi Fiksi dan Fakta. Yogyakarta: Pustaka Pelajar.

Saryono. (2009). Pengantar Apresiasi sastra. Malang: University Negeri Malang.

Septia, E., Marni, S., \& Armet, A. (2019). "Representasi Nilai Religi dan Kepengarangan Puisi-Puisi Karya Taufik Ismail". Poetika, 7(1), 32. https://doi.org/10.22146/poetika.v7i 1.43493

Sutarjo, A. (2013). Pembelajaran Nilainilai Karakter. Jakarta Rajawali Press.
Volume 3, Nomor 2, Juli 2021 ISSN 2655-3031 (P), 2655-7851 (O) DOI: http://dx.doi.org/10.29300/disastra.v3i2.4497 